\title{
Ano Internacional da Química no Brasil
}

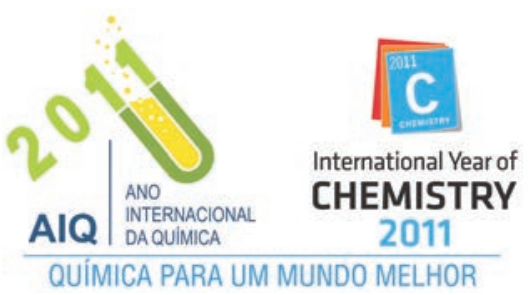

O Ano Internacional da Química-2011 (AIQ) no Brasil foi um projeto de sucesso. Foram realizadas em todo o país inúmeras ações e atividades comemorativas. A Sociedade Brasileira de Química (SBQ) coordenou as ações e, juntamente com a Associação Brasileira de Química-ABIQUIM, os Conselhos Regionais de Química, os museus de ciência, as universidades e escolas de ensino fundamental e médio, realizaram em torno de 150 projetos ao longo de 2011 e em todo o território brasileiro.

O Ministério de Ciência, Tecnologia e Inovação (MCTI), órgão governamental responsável pela formulação e implementação da política nacional de ciência e tecnologia, patrocinou 2 grandes projetos nacionais, que permitiram a realização de exposições, feiras de ciências, atividades artísticas e publicação de material de divulgação de ciência, entre outras ações, com a participação direta da SBQ.

A primeira ação da SBQ/AIQ, ainda em 2010, foi um concurso para gerar um selo comemorativo do AIQ em língua portuguesa. O selo vencedor foi reunido ao selo internacional, e passou a ser usado por universidades, escolas, órgãos públicos e indústrias privadas.

Foi criado um portal brasileiro comemorativo do AIQ, coordenado pela SBQ, www.quimica2011.org.br. Em 2011 o portal teve 520 mil visitas, um marco para um portal de ciências brasileiro.

Entre as várias sessões do portal, cabe destacar o projeto Química no Cotidiano, no qual foram publicados oito livros de divulgação de ciência, dois livros sobre experiências de quí- mica, um deles para os mais miúdos e uma exposição de painéis acompanhada de experiências. Na tabela 1 podem ser vistos os projetos que tiveram maior sucesso no portal e o número de acessos diretamente relacionados.

Em seguida são descritos alguns destes materiais.

\section{Livros "A Química no Cotidiano"}

Este livros, juntamente com o periódico Química Nova na Escola, uma publicação da SBQ para professores e alunos do ensino médio e graduação, foram reunidos num DVD e foram distribuídas 80 mil cópias no Brasil para as escolas públicas.

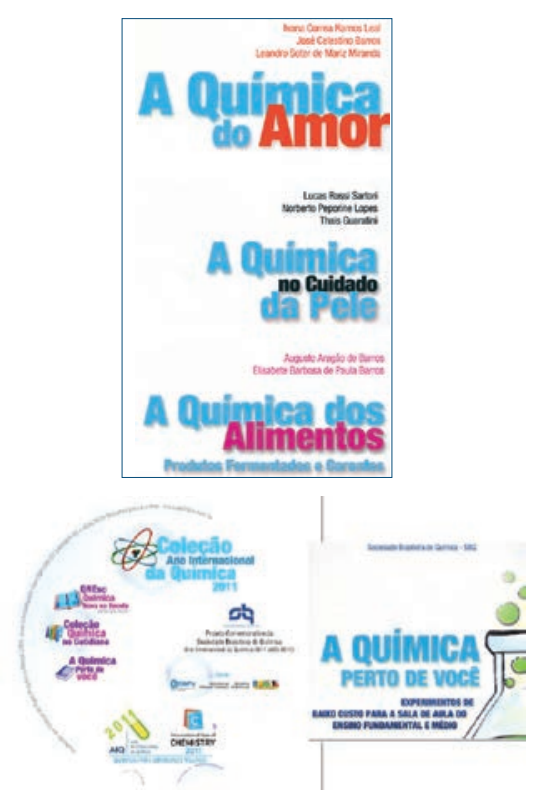

Coleção de livros “Química no Cotidiano”

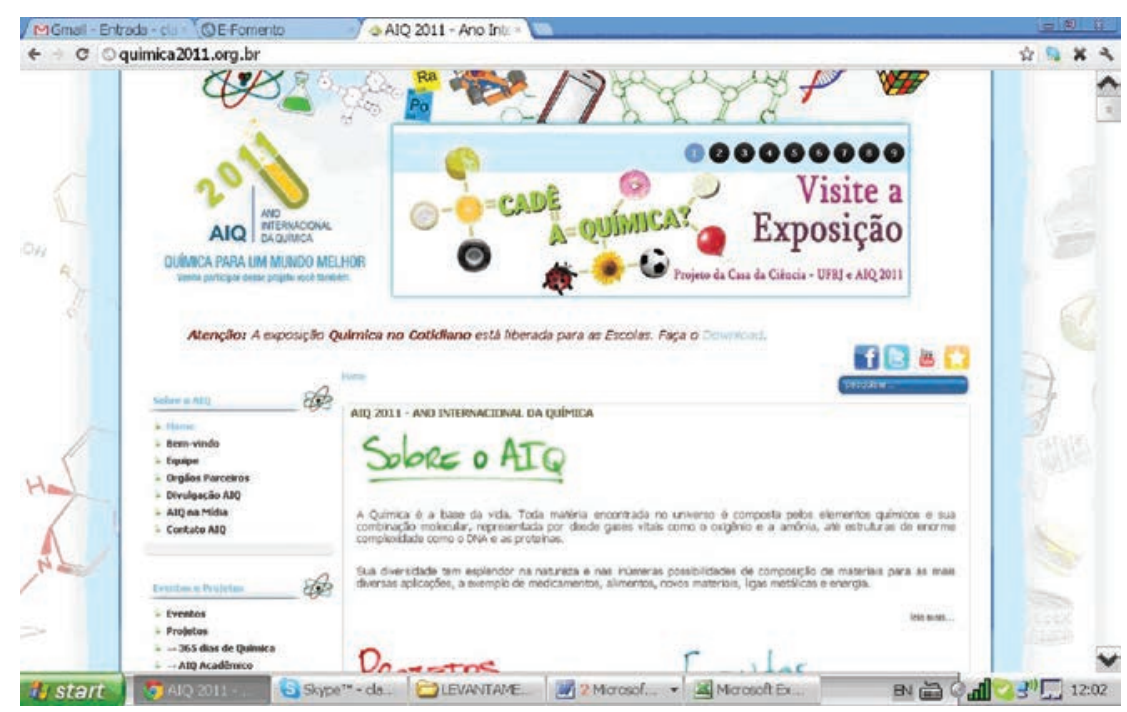

Portal www.quimica2011.org.br

Tabela 1 - Projetos que tiveram maior sucesso no portal www.quimica2011.org.br

\begin{tabular}{|l|c|}
\hline Sessão & $\begin{array}{c}\text { Número de visitas/downloads } \\
\text { (2011) }\end{array}$ \\
\hline 365 dias de química & 68524 \\
\hline Download da coleção de livros Química no Cotidiano & 23504 \\
\hline AlQ nas escolas (projetos) & 20196 \\
\hline Eventos pelo Brasil & 13497 \\
\hline Download do livro de experiências para miúdos & 13010 \\
\hline Download da exposição de painéis & 11990 \\
\hline
\end{tabular}




\section{Exposição de painéis "A Química no Cotidiano"}

No primeiro semestre de 2011, esta exposição, cujo objetivo foi apresentar a química em vários contextos, como na energia, agricultura, alimentação, saúde e comunicação, foi divulgada pelos museus de ciência em todo país, numa parceria com a SBQ. Em alguns estados houve uma intensa itinerância da exposição para as cidades do interior, com destaque em TVs e jornais. A partir de agosto de 2011, a exposição foi disponibilizada para acesso livre na rede, especialmente para escolas cadastradas e professores (11 990 downloads).

Outro projeto de sucesso no portal foi o 365 Dias de Química, que contou com entrevistas de profissionais da química e moléculas contextualizadas com manipulação de imagem. Como o nome do projeto reflete, foram adicionados ao portal, em cada dia, uma entrevista e uma molécula, um verdadeiro esforço conjunto de alunos e professores universitários.

O Brasil teve a oportunidade de receber vários cientistas agraciados com o prémio Nobel, como Ei-ichi Negishi (2010), Ada Yonath (2009), Richard R. Schrock (2005) and Kurt Wüthrich (2002), que abrilhantaram as ações brasileiras. Entre as inúmeras conferências e eventos científicos, destacou-se o ciclo de seminários da Fundação de Amparo a Pesquisa do Estado de São Paulo - FAPESP, com transmissão ao vivo para todo país e que contou com a presença da ex-presidente da IUPAC, Nicole Moreau.

A química também foi cantada, dançada e ergueu as velas das jangadas do estado de Alagoas, durante o carnaval de 2011. No Rio de Janeiro, subiu os morros cariocas, onde o prémio Nobel de 2008, Martin Chalfie, abriu a Semana Nacional de Ciência e Tecnologia - SNCT, medindo o $\mathrm{pH}$ das águas cariocas com alunos do Complexo do Alemão. E em todos os estados brasileiros houve comemorações criativas, como teatros, oficinas, concursos e exposições. Através da profícua parceria entre a SBQ, a Semana Nacional de Ciência e Tecnolo-

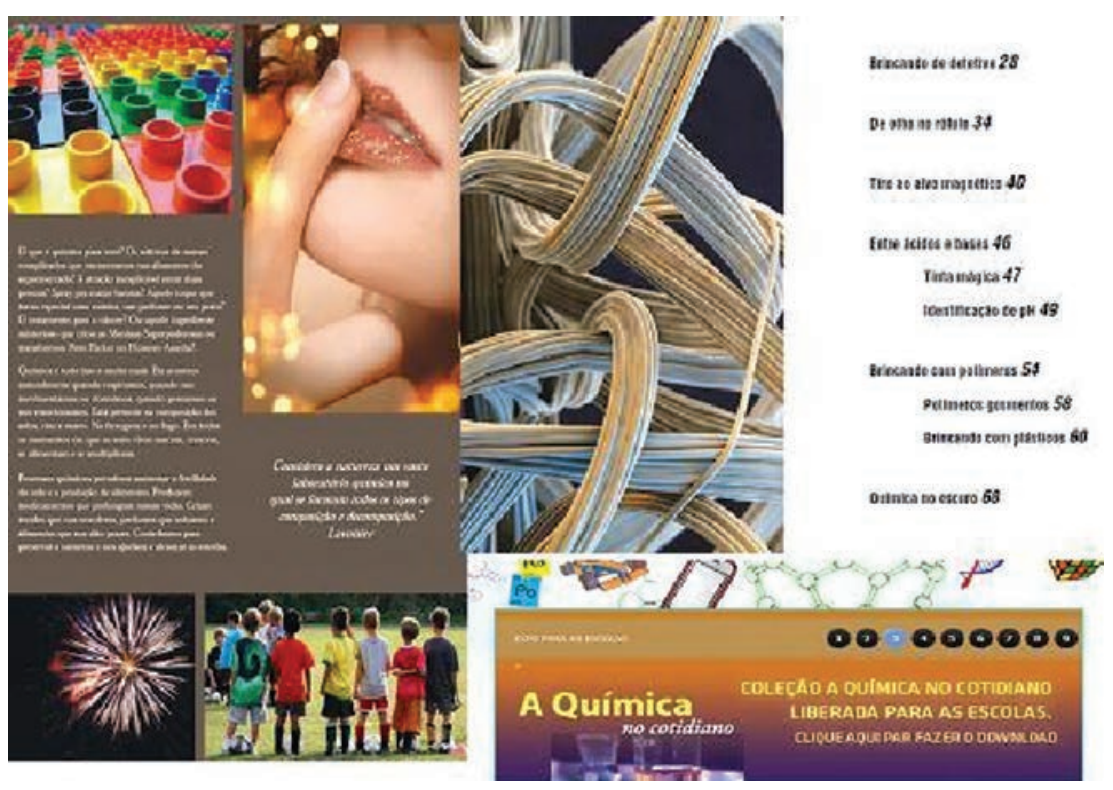

Painéis "A Química no Cotidiano"

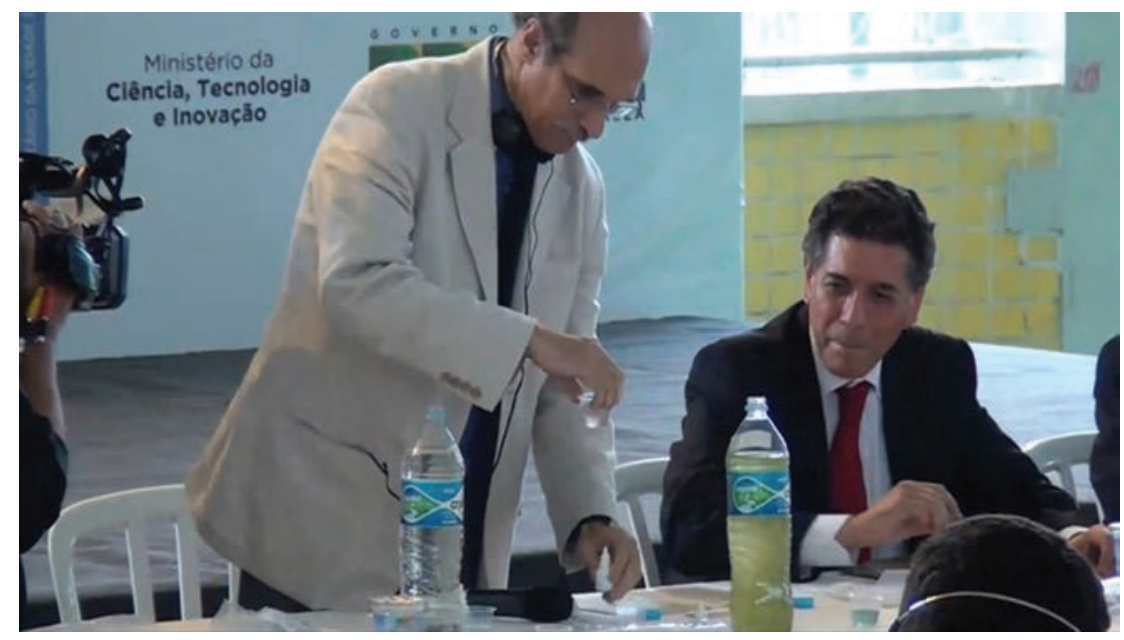

Dr. Martin Chalfie no Complexo do Alemão, Rio de Janeiro (outubro de 2011)
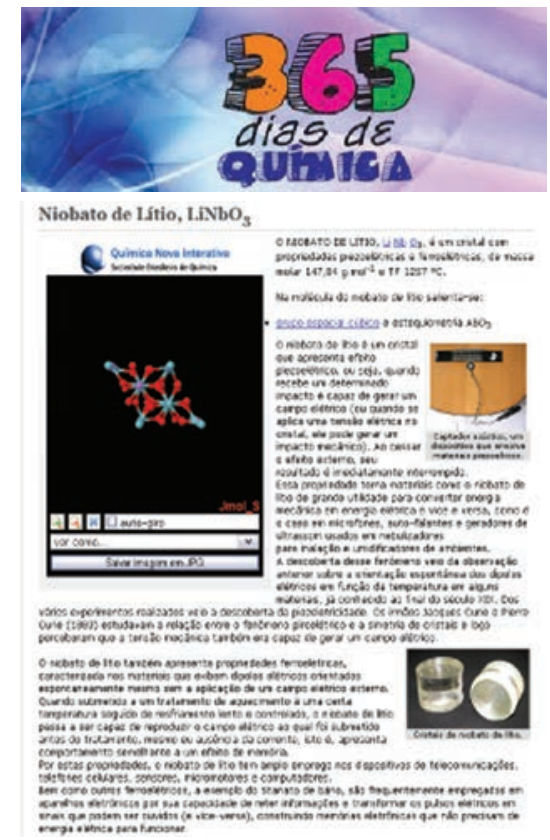

Projeto "365 Dias de Química”

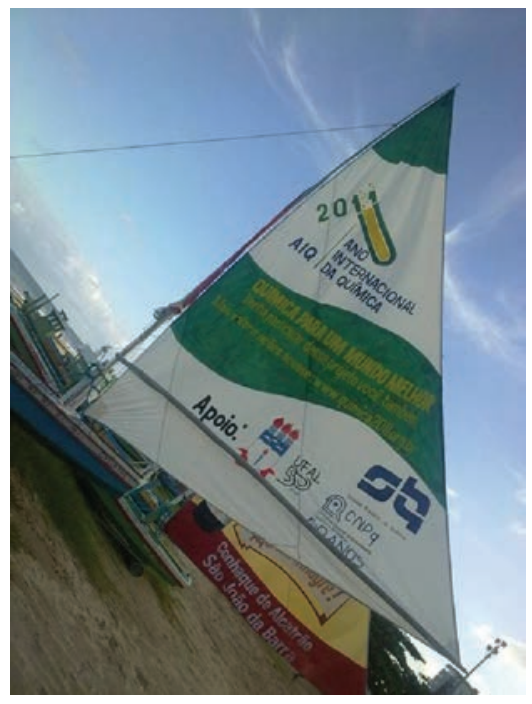

Carnaval de 2011 no estado de Alagoas 
gia (SNCT) e os Institutos Nacionais de Ciência e Tecnologia (INCT) de Energia e Meio Ambiente e de Materiais Nanoestruturados, a experiência global da água - pH do planeta, tornou-se a maior experiência até hoje já realizada nas escolas brasileiras. Esta ação, proposta pela Unesco e pela IUPAC, e lançada em janeiro de 2011 na abertura do AIQ - Paris, permitiu que jovens de todo mundo avaliassem a qualidade das águas de rios, lagos, nascentes e poços. No Brasil foram distribuídos cerca de 35000 kits, percorrendo inúmeras localidades brasileiras, a exemplo da aldeia Indígena Desana, no Rio Negro, Amazônia. No portal da Química Nova Interativa QNINT, da SBQ (www.qnint.sbq.org.br), é possível acompanhar o registo das experiências e quem as realizou, desbravando o território brasileiro com esta belíssima ação.

Foram apresentadas no país três grandes exposições sobre a química: Elementar, que abriu os trabalhos do AIQ, Cadê a Química e Química no Cotidiano. A primeira delas foi exposta na região sudeste e na Amazônia, e teve a sua tabela periódica interativa premiada no concurso International Awards-2012.

De realçar ainda a 34. ${ }^{\text {a }}$ Reunião da SBQ - RASBQ-2011, que contou com a presença de 4500 associados e com os Presidentes da IUPAC, ACS e RSC, que participaram ativamente em debates e proferiram palestras. A aproximação das sociedades coirmãs é uma meta que vem sendo trabalhada, pela SBQ, há alguns anos e que muito avançou no último biénio.

O projeto do AIQ no Brasil permaneceu ativo em 2012. Entre várias ações, de realçar a participação na Conferência da Rio + 20 , onde escolas e famílias discutiram e fizeram ensaios sobre a qualidade da água.

Só nos resta agradecer a todos os parceiros desta empreitada, cujos sonhos em torno de uma química mais consciente, bela e instigante puderam ser concretizados pelo esforço comunitário, num país onde a educação está muito aquém do que seu povo merece.

\section{Cláudia Moraes de Rezende}

(claudia.rezendeufrj@gmail.com)

Vice-presidente da SBQ e coordenadora das atividades do AIQ/SBQ/Brasil

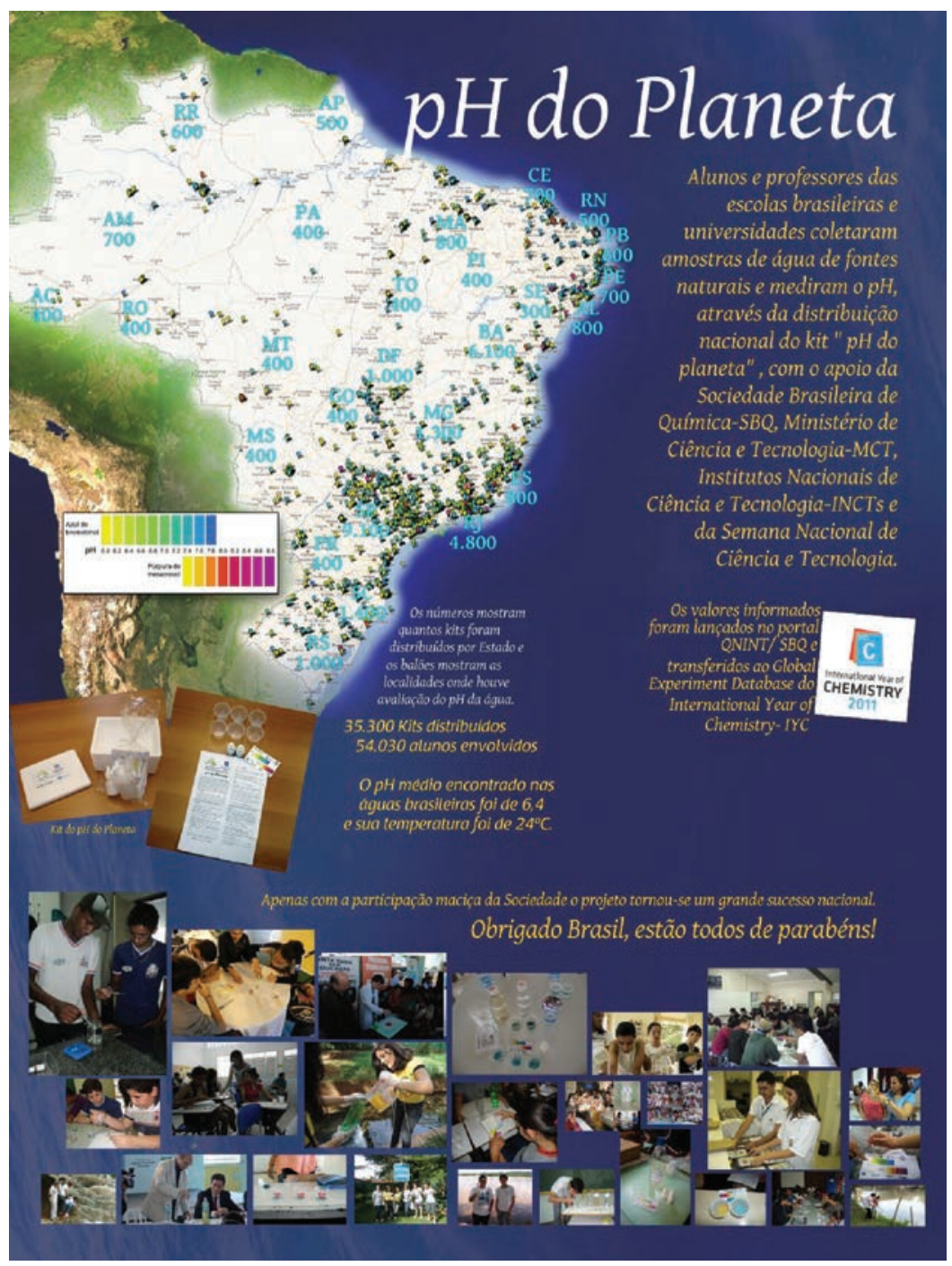

A experiência global da água - pH do planeta

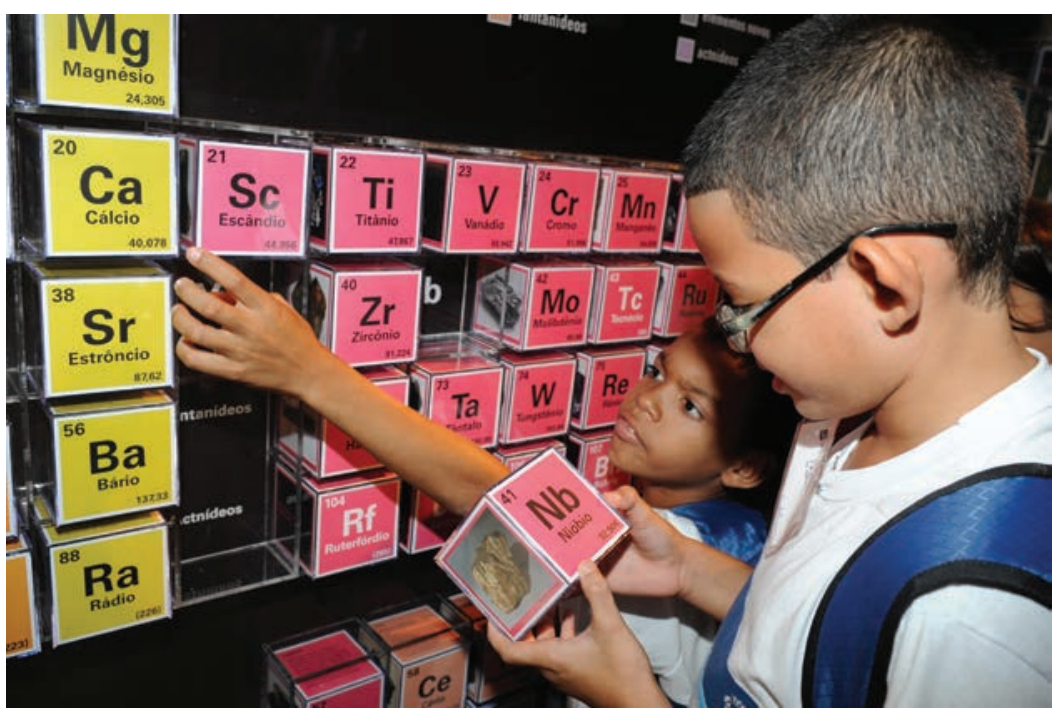

Tabela periódica interativa
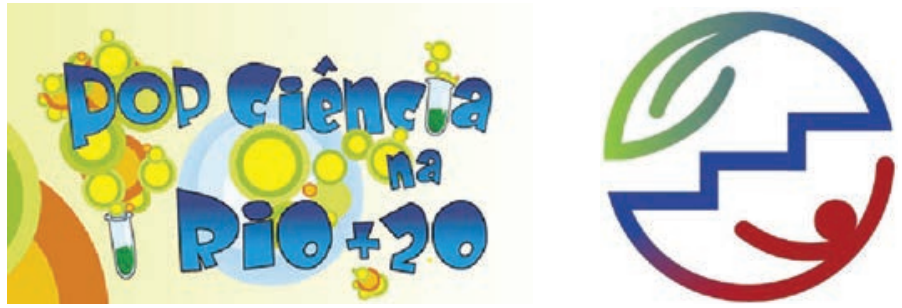

AIQ/Brasil na Conferência da Rio +20 


\section{Antoine-Laurent LAVOISIER}

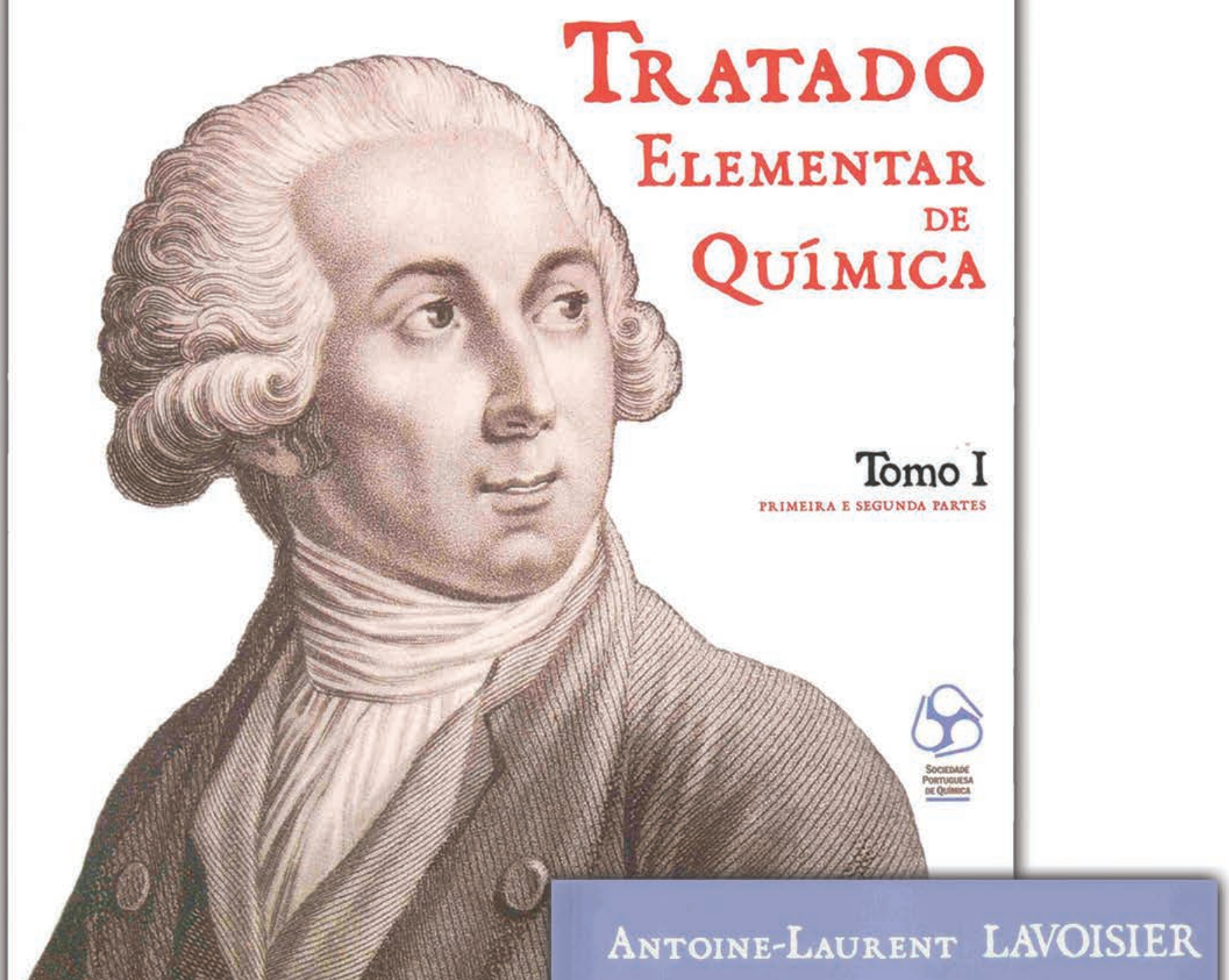

0 «Tratado Elementar de Química» de Antoine-Laurent Lavoisier (1743-1794), publicado em Paris em 1789, é um dos grandes clássicos da Química. Escrito na nova nomenclatura proposta também por Lavoisier, em conjunto com Morveau, Berthollet e Fourcroy, é a primeira obra de quimica moderna, abandonando-se as inadequadas designações de raízes alquímicas e a desacreditada teoria do flogisto. No tratado, ilustrado pela mulher do autor, Marie-Anne-Pierrette Paulze Lavoisier, formula-se de forma clara a conservação da matéria e define-se elemento químico de forma operacional.

No centenário da fundação da Sociedade Portuguesa de Química, publica-se finalmente uma cuidada tradução portuguesa do «Traité», modernizada e anotada.

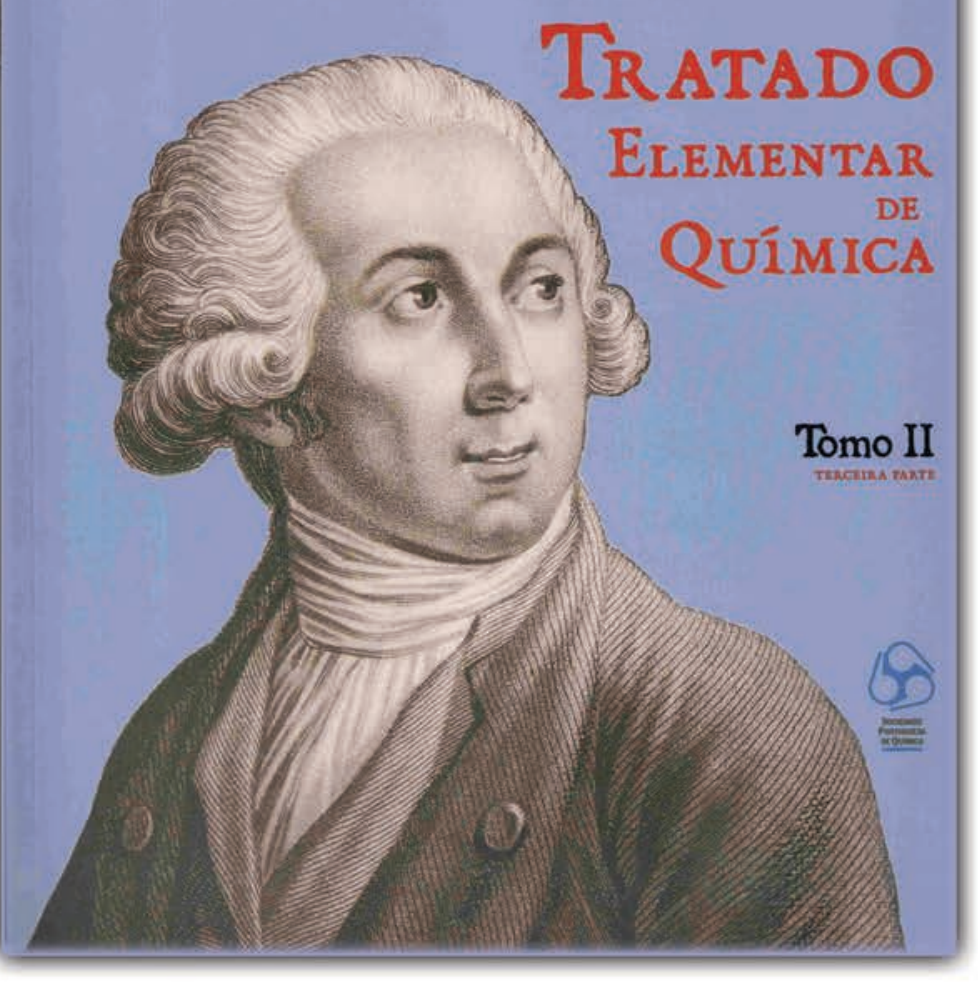

